\title{
РЕАЛИЗАЦИЯ ГОСУДАРСТВЕННОЙ ПОЛИТИКИ В ОБЛАСТИ ФИЗИЧЕСКОЙ КУЛЬТУРЫ И СПОРТА В РЕГИОНАХ РОССИЙСКОЙ ФЕДЕРАЦИИ
}

\author{
(C) 2021 Торкунов Олег Викторович \\ кандидат психологических наук, доцент \\ Российская международная академия туризма (Казанский филиал), Россия, Казань \\ E-mail: dudochnikov@yandex.ru \\ (c) 2021 Волкова Наталья Васильевна \\ кандидат социологических наук, доцент, \\ кафедра государственного и муниципального управления \\ Казанский (Приволжский) федеральный университет, Россия, Казань \\ E-mail: volk.nata2@list.ru \\ (c) 2021 Латыпова Карима Эдуардовна \\ магистр \\ Казанский инновационный университет имени В.Г. Тимирясова, Россия, Казань
}

Статья содержит исследование подходов к управлению отраслью физической культуры и спорта на региональном уровне. Проведен сравнительный анализ субъектов Приволжского федерального округа. В частности, проанализирована нормативно-правовая база, а также рассмотрены основы программно-целевого регулирования в указанной сфере. В заключение анализа проведен интегральный анализ показателей регионов, который позволяет оценить эффективность и комплексность регулирования физической культуры и спорта в субъектах РФ.

Ключевые слова: государственная политика, нормативно-правовое регулирование, государственные программы, стратегическое планирование, оценка эффективности, физическая культура, спорт, спортивные соревнования, инфраструктура, финансирование.

Целью исследования является проведение анализа функционирования государственной политики в области физической культуры и спорта, реализуемой на региональном уровне. В качестве объекта были выбраны пять регионов Приволжского федерального округа, а именно Республика Башкортостан, Республика Марий Эл, Республика Мордовия, Республика Татарстан, а также Удмуртская Республика. Указанные регионы имеют относительное сходство в своем социально-экономическом и географическом положении. Однако с точки зрения развития спорта они существенно отличаются друг от друга. Так, например, в Татарстане проходили такие масштабные спортивные события, как «Универсиада - 2013», Чемпионат мира по водным видам спорта, Чемпионат мира по футболу - 2018, тогда как, например, в Марий Эл подобных мероприятий не проводилось. Если обратиться к Чемпионату мира 2018 года, то можно отметить, что в двух республиках, Мордовии и Татарстане, проводились матчи и, соответственно, была создана спортивная инфраструктура для этого, тогда как в остальных рассматриваемых субъектах масштабных спортивных мероприятий не было. Кроме того, в рассматриваемых регионах в разной мере развиты различные виды спорта: например, Мордовия знаменита своей школой спортивной ходьбы, Башкортостан - своей хоккейной командой, Татарстан - хоккеем, футболом, волейболом и баскетболом. Указанные обстоятельства свидетельствуют о том, что опыт развития физической культуры и спорта в указанных субъектах существенно разнится.

Обратимся к результатам анализа и сравнения профильных региональных законов в области физической культуры и спорта в выбранных регионах РФ. Перечень рассматриваемых НПА указан в таблице 1.

На основании данных из таблицы 1 можно сделать следующие выводы. Во-первых, профильный закон есть в каждом из регионов, что уже говорит о важности спорта как общественного блага и, соответственно, разработанного направления государственной политики в этой области на уровне субъектов РФ. Во-вторых, на- 
Таблица 1. Профильные законы о физической культуре и спорте в регионах РФ

\begin{tabular}{|l|l|l|}
\hline \multicolumn{1}{|c|}{ Регион } & \multicolumn{1}{|c|}{ Региональный закон } & \multicolumn{1}{|c|}{ Время его принятия } \\
\hline $\begin{array}{l}\text { Республика } \\
\text { Башкортостан }\end{array}$ & $\begin{array}{l}\text { Закон Республики Башкортостан от 24.11.2008 № 68-3 «О фи- } \\
\text { Зической культуре и спорте в Республике Башкортостан» }\end{array}$ & $\begin{array}{l}\text { Раньше, чем Ф3 № 329 от } \\
\text { 4.12.2008 }\end{array}$ \\
\hline $\begin{array}{l}\text { Республика } \\
\text { Марий Эл }\end{array}$ & $\begin{array}{l}\text { Закон Республики Марий Эл от 30.12.2008 № 81-3 «О физиче- } \\
\text { ской культуре и спорте в РМЭ». }\end{array}$ & $\begin{array}{l}\text { Соответствует времени при- } \\
\text { нятия Ф3 № 329 }\end{array}$ \\
\hline $\begin{array}{l}\text { Республика } \\
\text { Мордовия }\end{array}$ & $\begin{array}{l}\text { Закон Республики Мордовии от 18.12.2008 № 136-3 «О физи- } \\
\text { ческой культуре и спорте в РМ» }\end{array}$ & $\begin{array}{l}\text { Соответствует времени при- } \\
\text { нятия Ф3 № 329 }\end{array}$ \\
\hline $\begin{array}{l}\text { Республика } \\
\text { Татарстан }\end{array}$ & $\begin{array}{l}\text { Закон Республики Татарстан от 8.10.2008 № 99-3РТ «О физи- } \\
\text { ческой культуре и спорте» }\end{array}$ & $\begin{array}{l}\text { Раньше, чем Ф3 № 329 от } \\
\text { 4.12.2008 }\end{array}$ \\
\hline $\begin{array}{l}\text { Удмуртская } \\
\text { Республика }\end{array}$ & $\begin{array}{l}\text { Закон Удмуртской Республики от 14.05.2019 № 26-Р3 «О фи- } \\
\text { зической культуре и спорте в УР» }\end{array}$ & $\begin{array}{l}\text { Существенно позже, чем Ф3 } \\
\text { № 329 }\end{array}$ \\
\hline
\end{tabular}

звание данных НПА соответствует названию профильного федерального закона № 329, что говорит о том, что региональное законодательство по своему содержанию является прямым продолжением и дополнением профильного федерального закона. В этих условиях важно обратиться к времени принятия каждого рассмотренного регионального НПА и сопоставить его с датой принятия ФЗ № 329.

Анализ показал, что в двух из пяти регионов законы приняты чуть раньше ФЗ № 329, в частности в Башкортостане и в Татарстане. Указанное расхождение нельзя считать критичным, в соответствии с этим нецелесообразно предполагать, что в региональных законах данных субъектов есть противоречия федеральному НПА. Компилятивный анализ указанных документов подтверждает данное предположение. Но при этом необходимо отметить следующее. Многие статьи законов РТ и РБ содержат указание на материал и положения ФЗ № 329. В качестве примера можно взять содержание статей «Основные понятия, используемые в законе». И в законе РТ, и в законе РБ в данной статье только отсылка к Ф3 № 329. Этот факт нарушает логику взаимосвязи НПА: региональные законы ссылались в своем содержании в изначальной редакции на Ф3, который на момент принятия региональных законов пока отсутствовал.

Далее обратимся к рассмотрению содержания профильных программ и подпрограмм в области физической культуры и спорта в выбранных регионах РФ. Перечень рассматриваемых программ указан в таблице 2 .

По итогам рассмотрения программноцелевых и организационных основ государственной политики в области физической культуры и спорта в отдельных регионах РФ, можно отметить, что большинство территорий пока подходят к развитию спорта с позиции общих стандартов, заложенных на федеральном уровне. Спорт рассматривается как не самое приоритетное направление, поэтому, как правило, политика в области спорта реализуется совместно с другим направлением политики, прежде всего, молодежной политики. Однако, как показал анализ региональных программ, более приоритетным и перспективным можно считать профильный подход к развитию спорта, поиск нестандартных решений и мероприятий, которые выгодно отличают такие региональные программы и сами субъекты, в которых они реализуются. Действительно ли такой подход более целесообразен и перспективен, позволит определить оценка результативности и эффективности государственной политики в области физической культуры и спорта в рассматриваемых регионах, которая описана ниже.

Показатели, выбранные для оценки эффективности и результативности, имеют разную природу. В комплексную оценку включены как абсолютные, так и относительные показатели, как финансовые данные, так и показатели, связанные с количеством единиц и людей. Использование подобных показателей позволило сделать оценку результативности и эффективности более объективной и, соответственно, более актуальной для использования в исследовании.

В силу расхождения показателей и единиц их измерения, для их совместного использования в рамках интегральной комплексной оценки была применена математическая методика нормирования. Сама комплексная оценка рассчитывалась как среднее арифметическое всех нормированных показателей, использованных при ее расчете, что позволило сохранить и отразить в итоговом результате взаимосвязь между различными данными и аспектами государственной политики в области спорта. Кроме того, данный метод позволил сделать соизмеримы- 
Таблица 2. Программно-целевые документы в области развития физической культуры и спорта в отдельных регионах РФ

\begin{tabular}{|c|c|c|}
\hline Регион & Программа/подпрограмма & НПА о программе/подпрограмме \\
\hline $\begin{array}{l}\text { Республика } \\
\text { Башкортостан }\end{array}$ & $\begin{array}{l}\text { Государственная программа «Развитие } \\
\text { физической культуры и спорта в Республике } \\
\text { Башкортостан», ее подпрограммы: «Развитие } \\
\text { массового спорта и физической культуры } \\
\text { в Республике Башкортостан», «Подготовка } \\
\text { спортивного резерва и спортсменов высшего } \\
\text { спортивного мастерства в Республике Баш- } \\
\text { кортостан» }\end{array}$ & $\begin{array}{l}\text { Постановление Правительства Респу- } \\
\text { блики Башкортостан от 25.12.2017 № } 613 \\
\text { «Об утверждении государственной програм- } \\
\text { мы «Развитие физической культуры, спорта и } \\
\text { молодежной политики в Республике Башкор- } \\
\text { тостан» и о внесении изменений в некоторые } \\
\text { решения Правительства Республики Башкор- } \\
\text { тостан» }\end{array}$ \\
\hline $\begin{array}{l}\text { Республика } \\
\text { Марий Эл }\end{array}$ & $\begin{array}{l}\text { Государственная программа «Развитие физи- } \\
\text { ческой культуры, спорта, туризма и моло- } \\
\text { дежной политики в Республике Марий Эл» } \\
\text { и ее подпрограммы «Развитие физической } \\
\text { культуры и массового спорта»; «Реализация } \\
\text { комплекса мер по развитию спорта высших } \\
\text { достижений и системы подготовки спортив- } \\
\text { ного резерва»; «Развитие инфраструктуры } \\
\text { физической культуры и спорта в Республике } \\
\text { Марий Эл» }\end{array}$ & $\begin{array}{l}\text { Постановление Правительства Республики } \\
\text { Марий Эл от 30.11.2012 № } 449 \text { «О государ- } \\
\text { ственной программе Республики Марий Эл } \\
\text { «Развитие физической культуры, спорта, } \\
\text { туризма и молодежной политики в Республи- } \\
\text { ке Марий Эл» на 2013-2025 годы» }\end{array}$ \\
\hline $\begin{array}{l}\text { Республика } \\
\text { Мордовия }\end{array}$ & $\begin{array}{l}\text { Государственная программа РМ «Развитие } \\
\text { физической культуры и спорта» и все под- } \\
\text { программы в ее составе }\end{array}$ & $\begin{array}{l}\text { Постановление Правительства Республики } \\
\text { Мордовия от 16.09.2013 № } 393 \text { «Об утвержде- } \\
\text { нии государственной программы Республики } \\
\text { Мордовия «Развитие физической культуры и } \\
\text { спорта» }\end{array}$ \\
\hline $\begin{array}{l}\text { Республика } \\
\text { Татарстан }\end{array}$ & $\begin{array}{l}\text { Государственная программа «Развитие } \\
\text { физической культуры и спорта в Республике } \\
\text { Татарстан на 2019-2023 годы» и все подпро- } \\
\text { граммы в ее составе }\end{array}$ & $\begin{array}{l}\text { Постановление Кабинета Министров Ре- } \\
\text { спублики Татарстан от 5.03.2019 № } 139 \\
\text { «Об утверждении государственной програм- } \\
\text { мы «Развитие физической культуры и спорта } \\
\text { в Республике Татарстан на 2019-2023 годы» }\end{array}$ \\
\hline $\begin{array}{l}\text { Удмуртская } \\
\text { Республика }\end{array}$ & $\begin{array}{l}\text { Государственная программа УР «Развитие } \\
\text { физической культуры, спорта и молодежной } \\
\text { политики» и ее подпрограммы «Развитие } \\
\text { физической культуры и содействие развитию } \\
\text { массового спорта», «Содействие развитию } \\
\text { спорта высших достижений и обеспечение } \\
\text { подготовки спортивного резерва» }\end{array}$ & $\begin{array}{l}\text { Постановление Правительства Удмуртской } \\
\text { Республики от 28.09.2015 № } 460 \text { «О государ- } \\
\text { ственной программе Удмуртской Республики } \\
\text { «Развитие физической культуры, спорта и } \\
\text { молодежной политики» }\end{array}$ \\
\hline
\end{tabular}

ми и сопоставимыми результаты комплексной оценки результативности политики и результаты комплексной оценки ее эффективности.

Сначала обратимся к результатам оценки результативности государственной политики в области физической культуры и спорта в рассматриваемых регионах.

В рамках данной комплексной оценки были использованы показатели, которые можно разделить на три блока:

1. Спортивная инфраструктура - данный блок показателей позволяет оценить обеспечение граждан объектами спорта, которые являются одним из важнейших условий занятия физической активностью. Данный блок показателей включает в себя в том числе:

- общее количество спортивных объектов;

- количество стадионов;

- количество плосткостных спортивных сооружений,
- количество спортзалов;

- количество бассейнов;

- количество спортивных сооружений на 100 человек - данный показатель является относительным и позволяет сравнить более объективно регионы друг с другом в части обеспеченности населения объектами спортивной инфраструктуры;

- фактическая единовременная пропускная способность объектов спорта (ЕПС) - указанный показатель позволяет не просто соотнести количество спортивных сооружений с общим количеством населения, а учесть и разные возможности спортивных сооружений принимать разное количество человек единовременно в своих стенах или на своей территории;

2. Спортивные кадры, ведущие занятия в области спорта и физической культуры - указанные показатели отражают второе важное условие занятия спортом - наличие тренера или 
наставника, обучающего правильной физической подготовке. Здесь рассмотрены следующие показатели:

- общее количество тренерских кадров в регионе;

- количество тренерских кадров на 100 тыс. чел. - указанный показатель позволяет соизмерить данные одного региона относительно других рассматриваемых субъектов в плане обеспеченности кадрами;

3. Финансирование государственной политики в области физической культуры и спорта указанные показатели позволяют отразить как объем работ в области спорта, который требовал финансовых вложений, так и вовлеченность различных источников в данный процесс. В данный блок вошли следующие показатели:

- общий объем финансирования;

- объем привлеченных в сферу спорта внебюджетных средств - указанный показатель важен для оценки, так как позволяет оценить заинтересованность частных субъектов в развитии спорта. Кроме того, ранее нами отмечалось, что во многих рассмотренных программах и НПА говорится о целесообразности вовлечения
НКО в процесс развития спорта, что связано, в том числе с их финансовыми вложениями в сферу физической культуры и спорта;

- доля внебюджетных средств в общем объеме финансирования;

- финансирование адаптивной физической культуры - данное направление политики сейчас становится очень актуальным, поэтому отдельно можно рассмотреть его финансирование в каждом из регионов.

Сведения по каждому из данных показателей рассматривались на начало 2020 года. Сведения были получены из различных источников, в том числе из Единой межведомственной информационно-статистической системы, официального сайта Федеральной службы государственной статистики. Также были использованы данные, представленные в годовых отчетах федерального Министерства спорта РФ и региональных профильных министерств, ответственных за реализацию государственной политики в области физической культуры и спорта. Нормированные показатели и результаты самой комплексной оценки отражены в таблице 3.

Таблица 3. Результаты оценки результативности государственной политики в области физической культуры и спорта регионах РФ

\begin{tabular}{|c|c|c|c|c|c|}
\hline & РБ & РМЭ & PM & PT & УР \\
\hline \multicolumn{6}{|c|}{ Спортивные сооружения } \\
\hline Всего спортивных сооружений, ед. & 1 & 0 & 0,03 & 0,87 & 0,19 \\
\hline Стадионы, ед. & 0,53 & 0,03 & 0 & 1 & 0,55 \\
\hline Плоскостные спортивные сооружения, ед & 1 & 0 & 0,03 & 0,47 & 0,06 \\
\hline Залы, ед. & 1 & 0 & 0,06 & 0,73 & 0,21 \\
\hline Бассейны, ед. & 0,9 & 0,03 & 0 & 1 & 0,3 \\
\hline $\begin{array}{l}\text { Количество спортивных сооружений на } 100 \text { тыс. } \\
\text { населения, ед }\end{array}$ & 1 & 0,06 & 0,07 & 0,62 & 0 \\
\hline ЕПС & 1 & 0 & 0,09 & 0,92 & 0,21 \\
\hline \multicolumn{6}{|c|}{ Показатели кадровой обеспеченности } \\
\hline Кадры тренерского состава, ед. & 0,83 & 0 & 0,15 & 1 & 0,34 \\
\hline $\begin{array}{l}\text { Количество кадров тренерского состава на } 100 \text { тыс. } \\
\text { населения, ед. }\end{array}$ & 0,2 & 0 & 1 & 0,53 & 0,7 \\
\hline \multicolumn{6}{|c|}{ Финансовые показатели } \\
\hline $\begin{array}{l}\text { Всего израсходовано на физическую культу и спорт } \\
\text { (тыс. руб.) }\end{array}$ & 1 & 0 & 0,06 & 0,68 & 0,28 \\
\hline $\begin{array}{l}\text { Доля расходов из внебюджетных источников в общей } \\
\text { сумме расходов на спорт, \% }\end{array}$ & 1 & 0 & 0 & 0,17 & 0,28 \\
\hline $\begin{array}{l}\text { Внебюджетные средства, использованные дл разви- } \\
\text { тии спорта, тыс. руб. }\end{array}$ & 1 & 0 & 0,01 & 0,24 & 0,13 \\
\hline $\begin{array}{l}\text { Расходы на развитие адаптивной физической культу- } \\
\text { ры, тыс. руб. }\end{array}$ & 0,6 & 0 & 0,09 & 0,15 & 1 \\
\hline Итоговая оценка & 0,85 & 0,01 & 0,12 & 0,64 & 0,33 \\
\hline Ранг региона & 1 & 5 & 4 & 2 & 3 \\
\hline
\end{tabular}


Из представленных в таблице 3 данных можно сделать следующие выводы. Оценки рассмотренных регионов по уровню результативности государственной политики в области спорта существенно варьируются. Лидером является Республика Башкортостан, далее идет Республика Татарстан, которая отстает на 0,21 пункта от РБ. Сравнивая результаты данных регионов, были сделаны следующие выводы. Существенное превосходство РБ дает лидерство по блоку финансовых показателей. Здесь Башкортостан имеет максимальные оценки по 3 из 4 показателей. При этом оценки РТ существенно уступают и находятся на уровне ниже среднего. Подобное расхождение можно объяснить следующим: Татарстан, начиная с момента подготовки к Летней Универсиале-2013, очень активно вкладывал средства в развитие спортивной инфраструктуры, последнее крупное спортивное мероприятие, принятое в РТ - это Чемпионат Мира по футболу в 2018 году. Соответственно, можно предположить, что в 2019 году расходы на строительство новых спортивных объектов, а именно на это выделяется большая часть средств, существенно сократились из-за отсутствия потребности в новых спортивных сооружениях. Это, в свою очередь, повлекло за собой общее сокращение расходов и, соответственно, оценок региона по показателям финансового блока.

Указанный вывод подтверждает и высокий уровень оценок РТ по инфраструктурному блоку показателей. Здесь разрыв оценок РТ и РБ существенно меньше, чем в финансовом блоке. Однако и здесь можно отметить лидерство РБ. Причем подчеркнем, Башкортостан опережает Татарстан по общим показателям, абсолютным и относительным если по количеству отдельных объектов, а именно бассейнов и стадионов, РТ опережает РБ, то по общей численности объектов спорта, а также по относительным показателям количества объектов на 100 тыс. чел. и ЕПС РТ уступает. Более существенной оказывается разница именно относительных показателей. Так, например, по общему количество спортивных объектов РБ опережает на 0,13 пунктов, тогда как по количеству объектов на 100 тыс. чел.- на 0,38 пунктов. По ЕПС оценки регионов расходятся несущественно, на 0,08 пункта, что говорит о примерно одинаковой обеспеченности людей местами в спортивных сооружениях, однако, несмотря на это, и тут Башкортостан опережает РТ.

Упущением и Башкортостана, и Татарстана можно считать кадровую обеспеченность в области физической культуры. Если по общему количеству тренерского состава регионы опережают остальных субъектов, причем в этом раз лидерство остается за Татарстаном, то по относительному показателю кадрового обеспечения в расчете на 100 тыс. чел. оба региона далеки от максимальной оценки, тогда как лидером оказывается Мордовия.

В отношении остальных регионов можно отметить следующее. Результативность государственной политики в области физической культуры и спорта в этих регионах существенно ниже медианной оценки. Аутсайдером является Республика Марий Эл, которая по большинству рассмотренных показателей имеет наименьшую оценку - 0. По некоторым показателям у данного региона показатели чуть выше, но и они остаются ниже 0,1 , то есть составляют менее $10 \%$ от максимально возможного результата. Аналогичная ситуация наблюдается и в Мордовии. Здесь оценка оказалась чуть выше только благодаря показателю «Количество тренерского состава на 100 тыс. чел.», по которому РМ имеет максимальную оценку 1. Относительно Удмуртской республики хотело бы отметит тот факт, что почти по всем показателям трех блоков данный регион имеет примерно одинаковые оценки, это позволяет региону занять место в середине рейтинга.

Государственная политика в области физической культуры и спорта в отдельных регионах РФ развита по-разному. Разнятся все основные аспекты данного направления политики: нормативно-правовой, организационный, программный аспекты, что сказывается на итогах исследуемой политики. Общий анализ показал, что условно регионы можно разделить на два блока: первый, в котором спорт рассматривается как отдельное важное направление политики, обособленное от других и реализующееся профильным органом, в других - как не столь масштабное направление политики, комбинированное с другими направлениями работы, прежде всего, с молодежной политикой. 


\section{Библиографический список}

1. Алиев М.Н., Джандаров Д. З. Значение физической культуры и спорта в патриотическом воспитании учащейся молодежи // Вестник ЯГУ.- 2009.- № 3.- С. 52-57.

2. Капленко А.М., Байорис А. М. Значение физической культуры и спорта в формировании эмоционального интеллекта // Интерэкспо Гео-Сибирь.-2020. - № 5.- С. 112-116.

3. Мансурова Г.И., Мансуров А.П. Роль и значение физической культуры и спорта в экономике // Вестник УлГТУ.- 2015.- № 4.- С. 59-61.

4. Новокрещенов В.В., Сунцов В. Ю. О взаимосвязи понятий «физическая культура», «спорт», «Физическая культура и спорт» в контексте управленческой практики // Теория и практика физической культуры. - 2013.№ $2 .-$ С. 77 .

5. Нуждёнов К.Э. Физическая культура и спорт: основы влияния на общество // Известия Пензенского государственного педагогического университета им. В. Г. Белинского. - 2012.- № 28.- С. 918-921.

6. Попова Н.В., БаянкинаД.Е. Физическая культура и спорт как условие предупреждения девиантного поведения студенческой молодежи // Проблемы современного педагогического образования. -2018. - № 1.- С. 295-298.

7. Закон Республики Татарстан от 8.10.2008 № 99-3РТ «О физической культуре и спорте».- URL: https://docs. cntd.ru/document/917030789 (Дата обращения: 28.04.2021).

8. Закон Республики Башкортостан от 24.11.2008 № 68-3 «О физической культуре и спорте в Республике Башкортостан»._URL: https://docs.cntd.ru/document/935115030 (Дата обращения: 28.04.2021).

9. Закон Республики Мордовии от 18.12.2008 № 136-3 «О физической культуре и спорте в PM»._URL: https:// docs.cntd.ru/document/819082813 (Дата обращения: 28.04.2021).

10. Закон Республики Марий Эл от 30.12.2008 № 81-3 «О физической культуре и спорте в PMЭ».- URL: https:// docs.cntd.ru/document/819084082 (Дата обращения: 28.04.2021).

11. Закон Удмуртской Республики от 14.04.2019 № 26-P3 «О физической культуре и спорте в УP».-URL: https:// docs.cntd.ru/document/553282655 (Дата обращения: 28.04.2021). 